\title{
Complicity with conservatism: the de-politicizing of multicultural and intercultural education
}

\author{
Paul C. Gorski* \\ Hamline University, USA
}

\begin{abstract}
Although multicultural education, a field dedicated to promoting equity and justice in education, continues to be the target of conservative critics, its contemporary crisis brews from within. The greatest danger to the movement toward equity and social justice that underlies multicultural education in the US comes from educators who ostensibly support its goals, but whose workcultural plunges, food fairs, human relations activities - reflect more of a compassionate conservative consciousness than an allegiance to equity. By reviewing conceptions of multicultural education from the field's leading US scholars and uncovering inconsistencies between these conceptions and the work people do under the guise of multicultural education, the author works toward a re-establishment of an authentically progressive notion of the field.
\end{abstract}

\section{Introduction}

A crisis threatens the movement for educational equity and social justice that underlies multicultural education in the US. The crisis is not about overt bigotry. It is not about struggling to introduce multicultural education into the mainstream consciousness. Instead, it is an internal crisis, a conservative reframing of multicultural education that focuses not on eliminating educational inequities, but on human relations and celebrating diversity (Hidalgo et al., 1996; Jackson, 2003). And while it is fueled in part by conservative voices, it is often cycled by us - the supposed champions of multicultural education - who believe, at least ostensibly, that all students are entitled to an equitable education.

As I consume the literature, attend conferences and workshops, and dialogue with colleagues, the signs are clear: The multicultural education most often practiced by teachers, administrators, staff developers, teacher educators, and others in the US is

\footnotetext{
*Hamline University, 1536 Hewitt Avenue, MS-A1720, St. Paul, MN 55104, USA. Email: gorski@edchange.org
} 
a conservatized, depoliticized version that does more to sustain inequities than to demolish them (Díaz-Rico, 1998). So, while it may be easier to blame right-wing politicians and educators for the conservative reframing of multicultural education, we first must turn the spotlight on ourselves.

That is what I intend to do here-to examine critically the ways in which we, multicultural educators and activists in the US, contribute to the crisis through practices and policies that do not reflect the spirit of multicultural education. I acknowledge that I am stepping into dangerous territory. My purpose is not to alienate present or potential allies or to criticize the work of people committed but still learning about equity and social justice (as we all are). My intention is to challenge all of us to examine our practice, activism, contributions to the literature, and other work. Is it consistent with our stated philosophies? Is it in the spirit of equity and social justice? Have we bowed to conservative pressures by softening our messages?

Secondly, I hope to share these trends with those working to implement multicultural or intercultural education in other countries so that we can strategize collectively on how to push back against the global movement for educational standardization and other conservative responses to the progress we have made toward equity and justice in various educational contexts around the world.

I present my challenge in three steps. First, I draw on the philosophy of major scholars to establish a set of principles for multicultural education in the US. These principles will provide the foundation against which I assess popular but regressive practices wrongly framed as 'multicultural education.' Secondly, I uncover some of the most common ways in which multicultural education 'insiders' participate in the conservatization of the field. Finally, I recommend strategies for re-establishing a field-wide vision of multicultural education that reasserts equity and social justice as its underlying goals.

\section{Defining principles of multicultural education}

In an attempt to identify a set of defining principles of multicultural education, I review conceptualizations produced by several of the field's pioneer voices, including Nieto (2000), Sleeter (1996), Grant (with Sleeter, 1998), and Banks (2004). I choose to focus on the field's leading scholars because, as Sleeter argues, 'one must distinguish between an approach as formulated by [multicultural education's] main theorists, and superficial applications of it that one often finds in schools as well as the literature' $(1996$, p. 8).

While each of these scholars frame multicultural education uniquely, they agree on several key principles:

(1) Multicultural education is a political movement and process that attempts to secure social justice for historically and presently underserved students.

(2) Multicultural education recognizes that, while some individual classroom practices are consistent with multicultural education philosophies, social justice is an institutional matter and as such, can be secured only through comprehensive school reform. 
(3) Multicultural education insists that comprehensive school reform can be achieved only through a critical analysis of systems of power and privilege.

(4) The underlying goal of multicultural education-the purpose of this critical analysis - is the elimination of educational inequities.

(5) Multicultural education is good education for all students.

A brief exploration of each of these principles will provide useful connection points for a later description of the conservatization of multicultural education.

\section{Securing social justice}

According to Banks (2004), a key element of multicultural education is the notion that all students are entitled to an 'equal opportunity to learn in school' (p. 3). Nieto agrees, explaining

[Multicultural education] challenges and rejects racism and other forms of discrimination in schools and society and accepts and affirms the pluralism (ethnic, racial, linguistic, religious, economic, and gender, among others) that students, their communities, and teachers represent. (2000, p. 305)

She continues, arguing that multicultural education must be explicitly antioppression, consciously standing against discrimination. Sleeter and McLaren (1995) affirm Banks and Nieto, pointing out the need for ongoing critique of the sociopolitical contexts of schooling. Sleeter (1996) describes this critical framework as 'a form of resistance to dominant modes of schooling, and particularly to white supremacy' (p. 2). It is not enough to learn about the cultures of our students without considering the significance of their positions (and ours) in the wider sociopolitical landscape. Instead, we must commit to ensuring, for example, that we empower girls as much as boys, call on girls as often as boys, and do not make assumptions about abilities based on our own socializations.

\section{Reforming schools comprehensively}

Likewise, the implementation of small changes within a traditional classroom or school system does not constitute multicultural education. Instead, multicultural education is broad based (Nieto, 2000), calling 'for the reform of the entire classroom and the school itself' (Grant \& Sleeter, 1998, p. 163). Nieto (2000) states that multicultural education must permeate school climate, culture, and practice-that it must be visible everywhere, including decision-making processes such as textbook adoption, behavior policies, and program assessment.

\section{Critically analyzing systems of power and privilege}

Because comprehensive school reform calls for institutional transformation that secures social justice, it must be based on a continual critical analysis of institutional power and privilege. According to Banks (2004, p. 23), 'To implement multicultural 
education in a school, we must reform its power relationships ... The institutional norms, social structures, cause-belief statements, values, and goals of the school must be transformed.'

Sleeter (1996) recognizes that, in order to reform power relationships in schools, we must first understand those relationships in a larger societal and global context. She argues that, 'multicultural education should also direct our attention to concentrations of power and wealth in the hands of a small elite' (1996, p. 137). Correspondingly, in their list of four goals of multicultural education, Grant and Sleeter (1998, p. 164) include promotion 'of awareness of the social issues involving unequal distribution of power and privilege that limits the opportunity of those not in the dominant group.' By nurturing this awareness, multicultural education uncovers 'policies and practices that are advantageous for some students at the expense of others' (Nieto, 2000, p. 315).

\section{Eliminating educational inequities}

Another principle of authentic multicultural education is equal opportunity (Grant \& Sleeter, 1998) - a movement to 'increase educational equity for a range of cultural, ethnic, and economic groups' (Banks, 2004, p. 7). So, once we uncover and acknowledge systems of power and privilege, multicultural education becomes a framework for exposing and eliminating the resulting educational inequities.

For example, it calls for teacher education programs to be reconceptualized to include awareness of the influence of culture and language on learning, the persistence of racism and discrimination in schools and society, and instructional and curricular strategies that encourage learning among a wide variety of students. (Nieto, 2000, p. 305)

Increased awareness among pre- and in-service teachers, administrators, activists, and scholars prepares us for more informed analyses of tracking, high-stakes testing, and other practices and policies that serve the interests of the privileged at the expense of other students (Nieto, 2000).

\section{Improving education for all students}

When multicultural education exposes racism, heterosexism, classism, and other inequities, opponents, such as Schlesinger (1998), denounce it as divisive. Grant and Sleeter (1998) challenge this denunciation, explaining that multicultural education does not value separatism, but cultural pluralism, a sharing of cultures for the benefit of the school community. In other words, while multicultural education advocates for disenfranchised students, it recognizes that the elimination of oppression benefits all students.

A consensus panel of interdisciplinary scholars, gathered by the Center for Multicultural Education, makes a particularly strong statement on this point:

An important goal of [US] schools should be to forge a common nation and destiny from the tremendous ethnic, cultural, and language diversity. To forge a common 
destiny, educators must respect and build upon the cultural strengths and characteristics that students from diverse groups bring to school ... Cultural, ethnic, and language diversity provide the nation and the schools with rich opportunities to incorporate diverse perspectives, issues, and characteristics into the nation and the schools in order to strengthen both. (Banks et al., 2001, p. 5)

Although Ladson-Billings (2003), Sleeter (2003), and others might criticize the UScentric, nationalistic spin of the panel's statement, what it clarifies is that, at its core, multicultural education institutionalizes inclusivity by engaging a broad set of worldviews that, woven together, afford everyone a deeper understanding of the world. In fact, Nieto (2000) argues that people from dominant groups benefit most from multicultural education. It is people from dominant groups, after all, who tend to be the most misled, miseducated citizens when it comes to sociopolitical and sociohistorical realities (Nieto, 2000).

\section{How we conservatize multicultural education}

Despite these principles, when I ask multicultural education professionals in the US to define multicultural education, their responses typically reflect more of a compassionate conservative consciousness than an allegiance to equity and justice. $\mathrm{My}$ prompt rarely elicits a sense of urgency to eliminate achievement gaps or the inequities that facilitate them. Their definitions almost never speak to the need to eradicate sexism, classism, heterosexism, racism, and other forms of oppression. Instead, a majority of well-intentioned equity advocates respond that multicultural education is about 'learning about other cultures' (which brings to mind the question, other than what?) or 'celebrating the joys of diversity.' And although such lessons and celebrations may be valuable educationally; they do not, when unattached from a transformative vision, move a classroom or school toward authentic multicultural education.

I have identified five sets of specific practices through which multicultural education professionals commonly undercut their commitment to equity and social justice: (1) being the change but not changing the being; (2) universal validation; (3) the whitening of the field; (4) the Ruby Payne syndrome; and (5) regressive 'multicultural' programs.

\section{Being the change but not changing the being}

In an article bridging feminist and multicultural education pedagogies, Zerbe Enns et al. challenge 'trainers and teachers to consider how the positions they hold influence their perceptions of reality and how their pedagogical strategies may oppress or empower particular groups or individuals' (2004, pp. 425-426). This theme-the need for reflection on one's prejudices-echoes throughout multicultural education literature (Nieto, 2000; Banks et al., 2001; Korn, 2002; Jackson, 2003; McKenzie \& Scheurich, 2004; Quezada \& Romo, 2004). It is, unquestionably, a crucial aspect of multicultural education.

But have we focused on changing hearts to the disregard of transforming institutions? Professional development on anti-racist education, when not whittled down 
to, for example, 'understanding Latino culture,' tends to focus on how to live in harmony, never reaching an authentic dialogue about racism in school policy (Cochran-Smith, 2004). And when these workshops do dig deeper into equity issues, the resulting dialogue and diversity awareness are not, in and of themselves, institutionally transformational. In fact, research indicates that anti-stereotyping workshops generally do not translate into multicultural teaching practice (Banks, 1993; Vavrus, 2002).

While greater awareness and self-reflection help us facilitate change, they do so at an institutional level only when they lead to policies and practices that support equity (Cochran-Smith, 2004). As captured by Woodard (2003, p. 167), 'awareness of forms of resistance is not enough; we must learn, teach, and apply deliberate strategies for resisting resistance.' Unfortunately, most staff development trainers, teacher educators, and, as a result, classroom teachers, fail to make this connection, approaching multicultural education 'as if it were divorced from the policies and practices of schools and from society' (Nieto, 2000, p. 9).

One can observe how multicultural education professionals perpetuate these dynamics in a variety of contexts. For example, a district-level diversity coordinator organizes a 'cultural plunge' for school administrators, taking them into a Hmong neighborhood to build their awareness about a growing percentage of their students. The administrators enjoy the soup at lunch and learn that the Hmong neighborhood is less dangerous than they had assumed. But the visit never translates into pedagogical shifts, hiring decisions (such as the employment of translators or Hmong-speaking staff), or other policies and practices that eliminate, or at least alleviate, the inequities Hmong students face.

Or a local school adopts an anti-discrimination statement that, while not explicitly referring to heterosexism, prohibits 'offensive language.' The principal organizes an after school workshop to discuss how such language can affect students' sense of safety. But because nobody has attached accountability measures to the use of heterosexist language, teachers who hear 'faggot' or other oppressive language in the hallway respond inconsistently if they respond at all. And because no enforceable policy is in place, teachers who do not respond are not held accountable for their support of heterosexism at the school.

One might argue that, in cases like these, multicultural education professionals facilitate a step forward - a step toward equity and social justice. But as we pour energy and resources into self-awareness, we divert attention from the larger goal: institutional transformation. We cannot assume, as we have, that changed hearts lead directly to changed policy and practices (Vavrus, 2002; Cochran-Smith, 2004). And we certainly cannot assume, as we have, that changed hearts, absent policy and accountability, are adequate for institutionalizing authentic multicultural education.

\section{Universal validation}

A common conservative complaint about multicultural education is that it is not 'multicultural' at all. That is, it comprises a set of beliefs that exclude people who do 
not think in the 'multicultural' box. Lawrence Auster, writing for FrontPageMagazine.com (2004), calls this 'the fraud of inclusion.' Jeanne McDonnell, writing for the Heritage Foundation, even blames people who fight racism for de facto segregation. She argues:

Sadly, some of those who fought so hard for desegregation now fight for re-segregation - in the name of multiculturalism and diversity. They forget the very lesson they taught America 40 and 50 years ago, the message of Martin Luther King Jr.: That people be judged not by the color of their skin but by what's in their hearts and minds. (McDonnell, 2003)

The insinuation is that multicultural education should not question the legitimacy of any point of view. And if we do, we fail to practice what we preach (or teach).

But multicultural education is not about validating all points of view. Nor is it politically neutral (Sleeter, 1996; Vavrus, 2002; Cochran-Smith, 2004). It is about identifying and eliminating educational inequities - a task not accomplished by validating oppressive beliefs or practices. Nieto (1995) explains:

some might call for 'equal time' for the Nazi point of view during World War II or for the plight of the White segregationists during the civil rights movement, claiming that all viewpoints have equal validity ... Here, then, is another clear instance where the curriculum might be reduced to no more than a variety of contesting folklores. (p. 197)

We often can observe this phenomenon in the ways in which multicultural education professionals address (or fail to address) heterosexism. In my experience, instructors, staff development specialists, and other multicultural education professionals in the US are more willing to excuse heterosexist attitudes than racist or sexist attitudes, especially if a student cites religion as justification for their prejudice. In fact, we may even classify heterosexism as a religious belief, as an attitude based on 'individual'-or worse, 'moral'—values. But heterosexism is oppression. And a multicultural education dedicated to equity and social justice must not excuse it or any other form of oppression, mistaking a dedication to the inclusion of silenced voices with a responsibility to include the oppressive voices that already pervade US social discourse. As multicultural education professionals, we bear the responsibility to be exclusive when doing so enables the eradication of inequity.

\section{The whitening of the field}

In 2003, the National Association for Multicultural Education (NAME) changed its bylaws to ensure race and gender diversity in its leadership:

In the event that persons elected to the NAME Board of Directors comprise an overly homogeneous group, based on race and ... the incumbent Board members or the founding members will take corrective action which may include the nullification of the election on the basis of the lack of diversity and initiate a new nomination and election process. (2003, p. 11)

NAME made this change in part because of a general commitment to diversity. But more importantly, NAME added this bylaw in response to observations that, as the 
leadership of US civil rights organizations becomes more white (or more male, upper class, or Christian) the organizations' politics become more conservative. Similarly, as white educators in the US grab hold of multicultural education, teaching classes, leading workshops, and contributing to the literature, the field has strayed from its equity base (Sleeter \& McLaren, 1995; Sleeter, 1996).

According to Sleeter (1996, p. 8), '[T] he politics of bringing about change has necessitated frequently couching arguments for school reform in language that white educators would attend to.' In other words, if I use the word 'racism' or 'white privilege,' I risk alienating participants who are intimidated by these terms. So, as Sleeter (1996) points out, many multicultural education professionals refrain from such terms, choosing, instead, to refer to their specialization as 'human relations.' While this may be an effective short-term strategy, it communicates to consumers of our work a lower-level expectation of multicultural thought and practice.

We also can observe the whitening of multicultural education in the design and implementation of classes and workshops. I sometimes lean on members of historically oppressed groups (people of color, women, people with disabilities, lesbians or gay men) to educate members of privileged groups. I may introduce a discussion on white privilege, then allow the dialogue to become a survey of the experiences of people of color. As a result, white participants (including myself) can avoid doing our own reflective work about the relationship between racism and whiteness. In other words, I 'whiten' the field-and contribute to the inequities I want to eradicate-when I design workshops and classes that focus on the cultural 'other' and fail to help participants unpack power, privilege, and oppression relationships (Sleeter, 1999).

Several other popular practices of multicultural education professionals reflect the whitening of the field. We whiten the field when we allow the most resistant, repressive voices to dictate the pace of our classes and workshops. We whiten it, too, when we focus on color-blindness, rendering racism and white supremacy invisible instead of exposing the ways they operate in schools and society (Winant, 1998; Vavrus, 2002; Cochran-Smith, 2004; McKenzie \& Scheurich, 2004). According to LadsonBillings (2003), these practices have 'forced scholars and activists to begin pushing against the ways dominant ideologies are able to appropriate the multicultural discourse' (p. 52).

I recognize the complexity of this problem. Most teachers and teacher educators in the US are, after all, white. But this is why I, a white male multicultural education professional, must ensure that I am not bleeding the politics and transformative nature out of the field, that I am not replicating my privilege in the way I frame multicultural education.

\section{The Ruby Payne syndrome}

Another way some of us contribute to the conservatization of multicultural education is by adopting models of trendy 'experts' without sufficient critical analysis of their work. I call this the 'Ruby Payne syndrome' because her book A Framework for 
Understanding Poverty (Payne, 2001) has, with little critical analysis, become standard fare in US multicultural education classes and workshops. (She is also becoming increasingly popular in Australia.)

A glance at other literature in the field should cause us to pause and reflect on this phenomenon. First, A Framework for Understanding Poverty is not about understanding poverty, what causes it, how educators consciously and unconsciously perpetuate it, or how the middle and upper classes maintain class privilege through the education system. For example, a recent study by the National Commission on Teaching and America's Future (NCTAF) (2004) shows that schools with large percentages of low-income students are more likely than schools with large percentages of wealthy students to have many teachers unlicensed in the subjects they teach, teacher turnover problems, teacher vacancies, limited access to computers and the Internet, inadequate facilities such as science labs, dirty or inoperative student bathrooms, evidence of vermin such as cockroaches and rats, and insufficient classroom materials.

But Payne (2001) fails to consider this sort of research and its connection to poverty. How can we understand poverty, particularly as it relates to teaching and learning, outside the context of these inequities?

We can find in A Framework for Understanding Poverty several illustrations of a conservative reframing of multicultural consciousness. For example, Payne states, 'Poverty is caused by interrelated factors: parental employment status and earnings, family structure, and parental education' (2001, p. 12). But she reverses the cause and effect relationship. Parental employment status and parental education do not cause poverty. Instead, they reflect the impact of poverty.

In fact, Payne's framework is devoid of sociopolitical context, and as a result, inconsistent with multicultural education's dedication to examining systems of power and privilege. Instead of tackling these systems, exposing ways in which they contribute to poverty through classist policies and practices like tracking, inequitable expectations, and high-stakes testing, she insists that we must understand the 'hidden rules' of poverty and teach students in poverty the rules that will help them navigate the system (p. 8). But the problem is not that students in poverty do not know the rules of the middle class or the wealthy. The problem, instead, is that the US education system is designed to benefit the middle class and wealthy at the expense of those in poverty (Kozol, 1992).

Why, then, have so many multicultural education professionals bought into Payne's framework? I believe the Ruby Payne Syndrome tempts us with the path of least resistance. Her work enables us to content ourselves by learning a set of cultural rules and helping a dominated group fit into a dominating system. In today's anxiety-ridden US education milieu, we may experience Payne's Framerwork as a reprieve from the difficult transformative work called for by Kozol (1992), hooks (2000), and others. Their work challenges us to be part of institutional change. Hers doesn't.

Although I have highlighted the popularity of Payne's work to illustrate a way in which some of us contribute to a conservative revision of multicultural education, we 
facilitate this conservatization through other channels as well. We facilitate it when we choose speakers or trainers based more on their entertainment value than their message. We facilitate it when we adopt resources that, in the name of multicultural education, contribute to stereotypes (Nieto, 2000; Cochran-Smith, 2004) or draw on deficit perspectives that essentially blame oppressed people for their own oppression. We facilitate it, too, when we offer workshops that never address the underlying issues of inequity such as racism or sexism, or that never provide a larger context for these inequities through an examination of corporate capitalism and US imperialism. And we facilitate it when we buy into any single framework-particularly one that is disconnected from what Nieto (2000, p. 148) calls the 'sociopolitical context of schooling.'

\section{Regressive 'multicultural' programs}

Well-meaning educators routinely disregard this sociopolitical context in the design of 'multicultural education' programs. These programs, including multicultural student clubs, service learning opportunities, and staff development workshops, when detached from a contextual understanding of equity and justice, tend to recycle biases and inequities (Nieto, 2000; Cochran-Smith, 2004).

For example, many schools attempt to achieve multicultural education by initiating multicultural student clubs. These clubs can serve educational purposes, providing opportunities for dialogue across difference and the development of political consciousness among students. Unfortunately, very few of these clubs receive the adult leadership needed to accomplish such goals. Instead, these clubs tend to host dances, organize cultural festivals, or sponsor international food fairs. Although students may learn valuable lessons through the cross-cultural collaboration necessary to coordinate 'cultural' events, they are concurrently helping to maintain inequity by focusing on surface-level programming instead of authentic equity concerns (Nieto, 2000). Equally important, we soften multicultural education when we invest in student organizations instead of addressing the hostile climates that make them necessary.

We contribute to the conservatization of multicultural education through other regressive programming. We contribute to it when we build service-learning programs that recycle social hierarchies (Cruz, 1990; O'Grady, 2000; Wade, 2000; Weah et al., 2000). Service learning opportunities in the US are often designed to send middle- or upper-middle-class students into working-class neighborhoods, not as equals, but as saviors coming to 'fix' the deficient communities. Students are rarely provided sufficient opportunity to learn about the complex nature of poverty (locally or globally), degenerative infrastructures in poor communities, or the ways in which their class privilege relates to others' repression. Instead, such programs tend to emphasize charity and cosmetic change (Kahne \& Westheimer, 1996; Densmore, 2000; Wade, 2000).

We contribute to it, too, when we send students for an afternoon in a 'diverse' neighborhood - what many multicultural educators in the US refer to as a 'cultural 
plunge - but never challenge them to consider privilege, oppression, and other social dynamics. When disconnected from an equity framework, these programs 'persist in preparing teachers to become one-dimensional multicultural technicians at best rather than developing into critically reflective multicultural curriculum developers' (Vavrus, 2002, p. 42). The question for multicultural educators is not whether teachers will eat in a restaurant operated by people outside their racial group, but whether we will secure equity for every student regardless of race (or any other social or cultural identity).

Underlying these concerns is the reality that too many educators at every level think of these sorts of programs as multicultural education. In fact, when we focus our time and resources on multicultural programming at the expense of institutional reform, we affirm and support the conservatization of multicultural education. As Díaz-Rico (1998, p. 71) explains, 'Anything less than dedication to the ideal of educational equity for students reduces multicultural education to a "stroll down ethnicity lane".'

\section{Practicing authentic multicultural education}

As we review the myriad ways in which multicultural education professionals contribute to this conservatization, we must conclude that one of the greatest dangers to the field comes from people committed philosophically to equity, but whose practices lack the transformative spirit of multicultural education. If we want to be part of the movement toward educational equity, we must rededicate ourselves to an authentic vision for multicultural education.

So how do we turn the multicultural education tide back toward equity and social justice? How can I assure, whatever my context, that I practice authentic multicultural education instead of bowing to conservative influences by promoting surfacelevel diversity programs?

As part of my own self-assessment process, I developed a series of guidelines consistent with an equity-oriented vision of multicultural education-the vision provided by scholar-practitioners such as Christine Sleeter, Sonia Nieto, and Carl Grant. I use these guidelines as a measuring stick for my teaching, research, and facilitation of professional development workshops. Each guideline is accompanied by a set of questions that provide departure points for continual reflection on a larger question: How does my work move my classroom, my school, the society, or the world closer to equity and justice?

\section{Guideline one: exceeding the additive}

I must refrain from referring to simple changes in curricula or programs as multicultural education. While these may be steps toward multicultural education, they are carried out too often as inconsequential shifts to inequitable conditions. Because it is by definition a holistic process, such shifts, disconnected from a larger transformational process, cannot be considered multicultural education. Am I contributing to a heroes and holidays or human relations notion of multicultural education? Do I understand 
multicultural education as a framework for equity in schools or as a series of individual programs? Am I, or is my school, counting on a multicultural student club to address diversity concerns in the school community?

\section{Guideline two: moving forward}

I continually must ask myself how my work moves education closer to equity. If I can't explain this to myself, I need to rethink how I'm framing multicultural education and expending my energy. Am I using resources earmarked for equity work or multicultural education for programs that, while fun, fail to challenge the status quo? Do my programs, though ostensibly related to multiculturalism, recreate or support existing stereotypes or hierarchies? Do I reframe multicultural education in depoliticized terms to make it more digestible to some people and thus less insistent on securing equity for others?

Guideline three: modeling equity and social justice

I must ensure that I do not replicate inequitable dynamics in courses and professional development workshops I facilitate or in my contributions to the literature. Am I putting the onus of responsibility on people from oppressed groups to teach people of privilege about discrimination? Am I designing courses and workshops at the pace of the most resistant participants thereby failing to provide leadership development to other participants? Am I challenging my students to study and understand dynamics of power and privilege, or only to examine experiences of oppressed groups?

Guideline four: healing the Ruby Payne syndrome

I must examine critically the resources I incorporate into classes and workshops, especially those that have become standard multicultural education fare. I must ascertain whether their popularity is due to depth and relevance or to comfort and an avoidance of responsibility. Am I choosing resources that encourage complex and critical thinking about equity and education? Am I providing a sociopolitical framework that delves into issues at an institutional level or do I deal with surface-level culture in a way that contributes to inequities?

\section{Guideline five: keeping it political}

I must remain committed to the political, transformative nature of multicultural education. I must not turn multicultural education into a relativistic concept that values every perspective. Am I validating oppressive statements as a matter of 'opinion'? Am I failing to confront heterosexism in order to be inclusive of people with heterosexist faith beliefs? Who benefits from the depoliticalization of multicultural education? Am I committed to criticizing dimensions of US identity and policy, such as imperialism, colonization, corporate capitalism, and Christian-centrism, that underlie inequities, even if people find them difficult to discuss? 
Guideline six: being a critically thinking student and teacher

I must frame multicultural education as an active process, remembering that being there philosophically is not the same as being there in practice. Am I connecting multicultural education to progressive policies and practices or focusing on changing attitudes? Am I continuing to learn about the complexities and intersections of educational inequities and their connections to larger sociopolitical issues?

\section{Guideline seven: contextualizing multicultural education}

I must facilitate experiences through which educators learn to examine equity concerns in a larger context of inequity. When these concerns are removed from this larger context, it is easier to believe they can be eradicated through band-aid approaches that never move toward educational equity. Am I contextualizing educational equity in a larger societal or global framework? Am I trying to understand or teach about the racial achievement gap outside the context of institutionalized racism? Can school inequities ever be eradicated without the eradication of equities from larger society?

\section{Conclusion}

Although we must continue to battle conservative US forces that recast multicultural education as a 'watering down' of traditional schooling, we can only do so effectively after we reflect on the ways in which we contribute to the deterioration of the field. Remembering the concept of multicultural education provided by leading voices in the field, we must reassess our work and whether it strengthens or softens the push toward equity in schooling. Only when we recommit ourselves to repoliticizing multicultural education will we be able to fill the gap in perception and experience that exists between the well-intentioned educators and policy-makers and the despite-the-good-intentions-disenfranchised students.

\section{Notes on contributor}

Paul C. Gorski is founder of EdChange.org and assistant professor in the Graduate School of Education at Hamline University. He is an active consultant, leading workshops for educators on equity and social justice. He is on the national board of the National Association for Multicultural Education and serves as president of his local chapter.

\section{References}

Auster, L. (2004) How multiculturalism took over America, FrontPageMagazine.org. Available online at http://www.frontpagemag.com/Articles/Printable.asp?ID=14164 (accessed 8 December 2004).

Banks, J. (1993) The canon debate, knowledge construction, and multicultural education, Education Researcher, 22(5), 4-14. 
Banks, J. (2004) Multicultural education: characteristics and goals, in: J. Banks \& C. Banks (Eds) Multicultural education: issues and perspectives (San Francisco, CA, Jossey-Bass), 3-30.

Banks, J., Cookson, P., Gay, G., Hawley, W., Irvine, J., Nieto, S., Schofield, J. \& Stephan, W. (2001) Diversity within unity: essential principles for teaching and learning in a multicultural society (Seattle, WA, Center for Multicultural Education).

Cochran-Smith, M. (2004) Walking the road: race, diversity, and social justice in teacher education (New York, Teachers College Press).

Cruz, N. (1990) A challenge to the notion of service, in: Kendall, J. C. and Associates (Eds) Combining service and learning: a resource book for community and public service (Raleigh, NC, National Society for Experiential Educators), 321-323.

Densmore, K. (2000) Service learning and multicultural education: suspect or transformative?, in: C. R. O'Grady (Ed.) Integrating service learning and multicultural education in colleges and universities (Mahwah, NJ, Lawrence Erlbaum), 45-58.

Díaz-Rico, L. T. (1998) Toward a just society: recalibrating multicultural teachers, in: R. Chávez Chávez \& J. O'Donnell (Eds) Speaking the unpleasant: the politics of (non) engagement in the multicultural education terrain (Albany, NY, State University of New York Press), 69-86.

Enns, C. Z., Sinacore, A. L., Ancis, J. R. \& Phillips, J. (2004) Toward integrating feminist and multicultural pedagogies, fournal of Multicultural Counseling and Development, 32 (Extra), 414-427.

Grant, C. \& Sleeter, C. (1998) Turning on learning: five approaches to multicultural teaching plans for race, class, gender, and disability (Upper Saddle River, NJ, Prentice-Hall).

Hidalgo, F., Chávez-Chávez, R. \& Ramage, J. (1996) Multicultural education: landscape for reform in the twenty-first century, in: J. Sikula, T. Buttery \& E. Guyton (Eds) Handbook of research on teacher education (2nd edn) (New York, Macmillan), 761-778.

Hooks, B. (2000). Where we stand: class matters (New York, Routledge).

Jackson, C. W. (2003) Crystallizing my multicultural education core, in: G. Gay (Ed.) Becoming multicultural educators: personal journey toward professional agency (San Francisco, CA, JosseyBass), 42-66.

Kahne, J. \& Westheimer, J. (1996) In service to what?: The politics of service-learning, Phi Delta Kappan, 77(2), 592-599.

Korn, C. (2002) Introduction: cultural transitions and curricular transformations, in: C. Korn \& A. Bursztyn (Eds) Rethinking multicultural education: case studies in cultural transition (Westport, CT, Bergin \& Garvey), 1-11.

Kozol, J. (1992) Savage inequalities: children in America's schools (New York, Crown).

Ladson-Billings, G. (2003) New directions in multicultural education: complexities, boundaries, and critical race theory, in: J. Banks \& C. Banks (Eds) Handbook of research on multicultural education (San Francisco, CA, Jossey-Bass), 50-65.

McDonnell, J (2003) The myth of multiculturalism, The Heritage Foundation. Available online at http://www.herigate.org/Press/Commentary/ed073103c.cfm?RefenderforPrint=1 (accessed 12 July, 2005).

McKenzie, K. B. \& Scheurich, J. J. (2004) Equity traps: a useful construct for preparing principals to lead schools that are successful with racially diverse students, Educational Administration Quarterly, 40(5), 601-632.

National Association for Multicultural Education (2003) Bylaws of the National Association for Multicultural Education (Washington, DC, Author).

National Commission on Teaching and America's Future (2004) Fifty years after Brown v. Board of Education: a two-tiered education system (Washington, DC: Author).

Nieto, S. (1995) From brown heroes and holidays to assimilationist agendas, in: C. Sleeter and P. L. McLaren (Eds) Multicultural education, critical pedagogy, and the politics of difference (Albany, NY, State University of New York Press), 191-220.

Nieto, S. (2000) Affirming diversity: the sociopolitical context of multicultural education (New York, Longman). 
O'Grady, C. R. (2000) Integrating service learning and multicultural education: an overview, in: C. R. O'Grady (Ed.) Integrating service learning and multicultural education in colleges and universities (Mahwah, NJ, Lawrence Erlbaum), 1-20.

Payne, R. K. (2001) A framework for understanding poverty (Highlands, TX, aha! Process).

Quezada, R. \& Romo, J. (2004) Multiculturalism, peace education, and social justice, Multicultural Education, Spring, 2-11.

Schlesinger, A. (1998) The disuniting of America: reflections on a multicultural society (New York, W.W. Norton).

Sleeter, C. (1996) Multicultural education as social activism (Albany, NY, State University of New York Press).

Sleeter, C. (2003) Teaching gobalization, Multicultural Education, 5(2), 3-9.

Sleeter, C. \& McLaren, P. (1995) Exploring connections to build a critical multiculturalism, in: C. Sleeter and P. L. McLaren (Eds) Multicultural education, critical pedagogy, and the politics of difference, 5-32 (Albany, NY, State University of New York Press).

Vavrus, M. (2002) Transforming the multicultural education of teachers: theory, research, and practice (New York, Teachers College Press).

Wade, R. C. (2000) Service-learning for multicultural teaching competency: insights from the literature for teacher educators. Equity $\mathcal{E}$ Excellence in Education, 33(3), 21-29.

Weah, W., Simmons, V. C. \& Hall, M. (2000) Service-learning and multicultural/multiethnic perspectives: from diversity to equity, Phi Delta Kappan, 81(9), 673-675.

Winant, H. (1998) Racial dualism at century's end, in: W. Lubiano (Ed.) The house that race built (New York, Vintage Books), 87-115.

Woodard, S. P. (2003) Clearing pathways for children to go forth, in: G. Gay (Ed.) Becoming multicultural educators: personal journey toward professional agency (San Francisco, CA, JosseyBass), 143-169. 
Copyright of Intercultural Education is the property of Routledge and its content may not be copied or emailed to multiple sites or posted to a listserv without the copyright holder's express written permission. However, users may print, download, or email articles for individual use. 